\title{
Evidence-based guideline update: NSAIDs and other complementary treatments for episodic migraine prevention in adults
}

Report of the Quality Standards Subcommittee of the American Academy of Neurology and the American Headache Society

S. Holland, $\mathrm{PhD}$

S.D. Silberstein, MD, FACP

F. Freitag, DO

D.W. Dodick, MD

C. Argoff, MD

E. Ashman, MD

Correspondence \& reprint requests to American Academy of Neurology: guidelines@aan.com

\section{See page 1337}

Supplemental data at www.neurology.org

\section{ABSTRACT}

Objective: To provide updated evidence-based recommendations for the preventive treatment of migraine headache. The clinical question addressed was: Are nonsteroidal anti-inflammatory drugs (NSAIDs) or other complementary treatments effective for migraine prevention?

Methods: The authors analyzed published studies from June 1999 to May 2009 using a structured review process to classify the evidence relative to the efficacy of various medications for migraine prevention.

Results: The author panel reviewed 284 abstracts, which ultimately yielded 49 Class I or Class II articles on migraine prevention; of these 49,15 were classified as involving nontraditional therapies, NSAIDs, and other complementary therapies that are reviewed herein.

Recommendations: Petasites (butterbur) is effective for migraine prevention and should be offered to patients with migraine to reduce the frequency and severity of migraine attacks (Level A). Fenoprofen, ibuprofen, ketoprofen, naproxen, naproxen sodium, MIG-99 (feverfew), magnesium, riboflavin, and subcutaneous histamine are probably effective for migraine prevention (Level B). Treatments considered possibly effective are cyproheptadine, Co-Q10, estrogen, mefenamic acid, and flurbiprofen (Level C). Data are conflicting or inadequate to support or refute use of aspirin, indomethacin, omega-3, or hyperbaric oxygen for migraine prevention. Montelukast is established as probably ineffective for migraine prevention (Level B). Neurology ${ }^{\circledR}$ 2012;78:1346-1353

\section{GLOSSARY}

AAN = American Academy of Neurology; $\mathbf{A E}=$ adverse effect; $\mathbf{C l}=$ confidence interval; $\mathbf{H B O}=$ hyperbaric oxygen; $\mathbf{N S A I D}=$ nonsteroidal anti-inflammatory drug; $\mathbf{O R}=$ odds ratio; $\mathbf{R} \mathbf{R}=$ relative risk.

Epidemiologic studies suggest approximately 38\% of migraineurs need preventive therapy, but only $3 \%-13 \%$ currently use it. ${ }^{1}$ In 2000 , the American Academy of Neurology (AAN) published guidelines for migraine prevention. ${ }^{2,3}$ Since then, new clinical studies have been published on the efficacy and safety of migraine preventive therapies. This guideline seeks to assess this new evidence to answer the following clinical question: For patients with migraine, which anti-inflammatory or complementary treatments are effective for prevention, as measured by reduced migraine attack frequency, reduced number of migraine days, or reduced attack severity? This article addresses the efficacy and safety of histamines/antihistamines; nonsteroidal anti-inflammatory drugs (NSAIDs) and analgesics; and several herbal, vitamin, and mineral preparations, whereas a companion article addresses standard pharmacologic treatments for migraine prevention. ${ }^{4}$

\section{DESCRIPTION OF THE ANALYTIC PROCESS}

The AAN and the American Headache Society participated in the development process. An author

From the Armstrong Atlantic State University (S.H.), Savannah, GA; Thomas Jefferson University (S.D.S.), Jefferson Headache Center, Philadelphia, PA; Comprehensive Headache Center (F.F.), Baylor University Headache Medicine Center, Dallas, TX; Mayo Clinic (D.D.), Scottsdale, AZ; New York University School of Medicine (C.A.), Albany; and Elmendorf Air Force Base (E.A.), AK.

Appendices e-1-e-5 and tables e-1 and e-2 are available on the Neurology ${ }^{\circledR}$ Web site at www.neurology.org.

Approved by the Quality Standards Subcommittee on February 19, 2011; by the Practice Committee on June 19, 2011; by the AHS Board of Directors on March 29, 2012; and by the AAN Board of Directors on November 7, 2011.

Study funding: This guideline was developed with financial support from the American Academy of Neurology and the American Headache Society. None of the authors received reimbursement, honoraria, or stipends for their participation in the development of this guideline.

Go to Neurology.org for full disclosures. Disclosures deemed relevant by the authors, if any, are provided at the end of this article. 
Table 1 Classification of migraine preventive therapies (available in the United States)

\begin{tabular}{|c|c|c|c|c|}
\hline $\begin{array}{l}\text { Level A: Medications } \\
\text { with established } \\
\text { efficacy ( } \geq 2 \text { Class I } \\
\text { trials) }\end{array}$ & $\begin{array}{l}\text { Level B: Medications } \\
\text { are probably } \\
\text { effective (1 Class I } \\
\text { or } 2 \text { Class II studies) }\end{array}$ & $\begin{array}{l}\text { Level C: Medications } \\
\text { are possibly } \\
\text { effective (1 Class II } \\
\text { study) }\end{array}$ & $\begin{array}{l}\text { Level U: Inadequate } \\
\text { or conflicting data } \\
\text { to support or refute } \\
\text { medication use }\end{array}$ & $\begin{array}{l}\text { Other: Medications that } \\
\text { are established as } \\
\text { possibly or probably } \\
\text { ineffective }\end{array}$ \\
\hline $\begin{array}{l}\text { Herbal preparations, } \\
\text { vitamins, minerals, } \\
\text { and other }\end{array}$ & NSAIDs & NSAIDs & NSAIDs & Probably not effective \\
\hline \multirow[t]{11}{*}{ Petasites } & Fenoprofen ${ }^{a}$ & Flurbiprofen ${ }^{a}$ & Aspirin & $\begin{array}{l}\text { Leukotriene receptor } \\
\text { antagonist }\end{array}$ \\
\hline & Ibuprofen ${ }^{a}$ & Mefenamic acid ${ }^{a}$ & Indomethacin ${ }^{a}$ & Montelukast \\
\hline & Ketoprofen ${ }^{a}$ & $\begin{array}{l}\text { Herbal preparations } \\
\text { vitamins, minerals, } \\
\text { and other }\end{array}$ & $\begin{array}{l}\text { Herbal preparations } \\
\text { vitamins, minerals, } \\
\text { and other }\end{array}$ & \\
\hline & Naproxen ${ }^{a}$ & Co-Q10 & Omega-3 & \\
\hline & Naproxen sodium ${ }^{a}$ & Estrogen & Other & \\
\hline & $\begin{array}{l}\text { Herbal preparations, } \\
\text { vitamins, minerals, } \\
\text { and other }\end{array}$ & Antihistamine & baric & \\
\hline & Magnesium & Cyproheptadine & & \\
\hline & MIG-99 (feverfew) & & & \\
\hline & Riboflavin & & & \\
\hline & Histamines & & & \\
\hline & Histamine SC & & & \\
\hline
\end{tabular}

${ }^{a}$ Indicates classification based on original guideline and new evidence not found for this report.

panel of headache and methodologic experts was assembled to review the evidence.

Computerized searches of the MEDLINE, PsycINFO, and CINAHL databases identified new studies. The search strategy used the MeSH term "headache" (exploded) and a published search strategy for identifying randomized controlled trials in adults that were published in English between June 1999 and May 2007. Additional MEDLINE searches revealed studies published through May 2009, which were reviewed and are included as supplemental articles.

Studies of NSAIDs and complementary treatments available in the United States were included in the analysis if they randomized patients with migraine to the agent under study or a comparator treatment (including placebo) and utilized masked (blinded) outcome assessment. At least 2 panelists independently reviewed each selected study and rated it using the AAN therapeutic classification of evidence scheme (appendix e-3 on the Neurology ${ }^{\circledR}$ Web site at www.neurology.org). Differences in ratings were resolved by author panel discussion.

ANALYSIS OF EVIDENCE The original search identified 179 articles and included pharmacologic and complementary treatments and NSAIDs. The supplemental search from 2007 to 2009 yielded an additional 105 articles. Of the total 284 articles, 15 were classified as Class I or Class II and identified as relating to NSAIDs and complementary treatments; they are reviewed herein. Clinical studies reviewed were limited to those assessing efficacy of NSAIDs and complementary treatments for prevention of episodic migraine in adults (e.g., $<15$ days/month). Studies were excluded if they assessed the efficacy of therapeutic agents for prevention or treatment of chronic migraine, intractable migraine, tension-type headache, or headache in adolescents or children. Also excluded were studies that assessed acute migraine treatment, migraine aura treatment or prevention, or nonpharmacologic treatments. Studies using quality of life measures, disability assessment, or nonstandardized outcomes as primary efficacy endpoints were not included. NSAIDs and complementary treatments not commonly or readily available in the United States are not reviewed in this guideline.

Since the 2000 guideline publication, the AAN revised its evidence classification criteria to include study completion rates. Studies whose completion rates are below $80 \%$ were downgraded.

We found no additional Class I or Class II studies published since the original guideline for fenoprofen, ibuprofen, ketoprofen, naproxen, naproxen sodium, or indomethacin. Recommendations regarding these treatments are based on the evidence reviewed in the original guideline (denoted in table 1).

Following is a summary of Class I and Class II evidence for the efficacy of NSAIDs and comple- 
mentary treatments for migraine prevention. Assessment of relative safety and tolerability of these agents as compared with placebo or other active treatments falls outside the scope of this efficacy assessment, but general information regarding safety and tolerability is included. Additionally, efficacy results from the summarized trials may be dependent on study design, including study duration (8 weeks vs 6 months), medication doses (low vs high), and dosing regimens and titrations - all of which may influence efficacy onset, relative efficacy, and quality of the evidence.

Histamines/antihistamines/leukotriene receptor antagonists. In the 2000 guideline, there were no studies of histamines, antihistamines, or leukotriene receptor antagonists for migraine prevention. Since that publication, several studies of histamine, cyproheptadine, and montelukast have been performed.

Histamine. Three Class II single-center studies (all from the same center) show the efficacy of histamine for migraine prevention. ${ }^{5-7} \mathrm{~N}$-alpha-methyl histamine (1-10 ng 2 times/week) SC injections reduced attack frequency from baseline as compared with placebo. ${ }^{5}$ Headache frequency at 4 weeks was reduced from 3.8 to 0.5 in the histamine group, as compared with reduction from 3.6 to 2.9 attacks for placebo $(p<0.0001)$. Histamine was statistically superior to placebo at all treatment visits through 12 weeks for reduction in migraine frequency, severity, and duration $(p<0.0001)$. Transient itching at the injection sites was the only reported adverse effect (AE), but it did not reach significance.

In a second Class II study, histamine was shown to be as effective as sodium valproate in reducing attack frequency and better than sodium valproate in reducing headache duration and intensity. ${ }^{6}$ Specifically, both sodium valproate $500 \mathrm{mg} /$ day and histamine (1-10 ng 2 times/week) SC injections improved headache frequency, duration, and intensity as early as 8 weeks following treatment when compared with baseline $(p<0.05)$. No patients on histamine presented with AEs. Conversely, 37\% of patients on sodium valproate experienced nausea, $34 \%$ had tremor, $24 \%$ had weight gain, and $12 \%$ had alopecia.

A third study reported the efficacy of histamine in migraine prevention as compared with topiramate. Topiramate $100 \mathrm{mg} /$ day was compared with histamine (1-10 ng 2 times/week SC), and both active treatments showed improvement over baseline measures for attack frequency, intensity, and use of rescue medication. ${ }^{7}$ Eleven percent $(5 / 45)$ of subjects treated with histamine withdrew from the histamine group because they were not satisfied with the speed of results, although no AEs were reported. Few subjects reported transitory burning and itching at the injection site. Similar AEs and withdrawal rates (for slow reaction speed) were reported for the sodium valproate study. ${ }^{6}$ Histamine SC was associated with transitory burning and itching at the injection site.

Cyproheptadine. A single Class II study (described in the companion guideline) showed cyproheptadine ( $4 \mathrm{mg} /$ day) was as effective as propranolol $(80 \mathrm{mg} /$ day) in reducing migraine frequency and severity. ${ }^{8}$

Montelukast. One Class I study of montelukast (20 $\mathrm{mg}$ ) for migraine prevention reported no significant difference between treatments in the percentage of patients with $\mathrm{a} \geq 50 \%$ decrease in migraine attack frequency per month $(15.4 \%$ for montelukast vs $10.3 \%$ for placebo [odds ratio $(\mathrm{OR})=1.64$; confidence interval (CI) $0.64-4.20]$ ). ${ }^{9}$ As compared with the placebo group, the montelukast group reported no differences in incidence, frequency, or severity of AEs in this 3-month treatment phase.

Conclusions. Histamine SC is established as probably effective (3 Class II studies) for migraine prevention. Cyproheptadine is possibly effective for migraine prevention and possibly as effective as propranolol for migraine prevention (single Class II study). Montelukast is probably ineffective for migraine prevention (1 Class I study; table 1).

NSAIDs. The efficacy of NSAIDs for migraine prevention was reported in the original guideline, including 23 controlled trials of 10 different NSAIDs that showed a modest but significant benefit for naproxen sodium, with similar trends for flurbiprofen, ketoprofen, and mefenamic acid. In the absence of new clinical reports, recommendations for NSAID use for migraine prevention are based on data from the original guideline. Regarding aspirin, new clinical evidence is available and included herein.

Aspirin. In the original guideline, studies of aspirin were found to have conflicting results. Since the original report, 2 additional Class II studies have been reported. As summarized in the companion article, aspirin was found to be as effective as metoprolol for migraine prevention. ${ }^{10}$ In a second study, aspirin $100 \mathrm{mg}$ in combination with vitamin E 600 IU every other day was compared with placebo in combination with vitamin E. ${ }^{11}$ No differences were noted between aspirin and placebo treatments for migraine frequency or severity at 12 months or 36 months.

Conclusions. The efficacy of aspirin for migraine prevention is unknown (conflicting Class II studies; table 1).

Clinical context. Regular or daily use of selected NSAIDs for the treatment of frequent migraine attacks may exacerbate headache because of development of a condition called medication overuse 
headache. ${ }^{12}$ Therefore, use of aspirin, selected analgesics, and NSAIDs may exacerbate headache; use of these agents in migraine prevention studies may confound the clinical interpretation of the study results.

Herbal preparations, vitamins, minerals, and other interventions. Since the original guideline, additional studies have been identified that assess the efficacy of Co-Q10, estrogen, hyperbaric oxygen (HBO), magnesium, MIG-99, omega-3, Petasites, and riboflavin for migraine prevention.

Co-Q10 (water-soluble disbursable form of Co-Q10). One small Class II study showed that Co-Q10 100 mg TID was significantly more effective than placebo in reducing attack frequency from baseline to 4 months following treatment. ${ }^{13}$ The $50 \%$ responder rate for attack frequency ( $\geq 50 \%$ reduction) was $47.6 \%$ for CoQ10 vs $14.3 \%$ for placebo $(p=0.02)$. The actual reduction in attack frequency was $-1.9 \pm 1.9$ for CoQ10 and $0.09 \pm 1.9$ for placebo $(p=0.05)$. One patient withdrew from the Co-Q10 treatment group because of cutaneous allergy.

Estrogen. A combination of soy isoflavones (60 $\mathrm{mg})$, dong quai (100 mg), and black cohosh (50 mg) (each component standardized to its primary alkaloid) reduced migraine attack frequency vs placebo in a small Class II study. ${ }^{14}$ The mean frequency of menstrually associated migraine attacks during weeks 9-24 was reduced from $10.3 \pm$ SEM 2.4 in patients treated with placebo to $4.7 \pm$ SEM $1.8(p<0.01)$ in patients treated with the phytoestrogen preparation.

In a second Class II trial, percutaneous estradiol was applied 6 days before the first full day of bleeding up to and including the second full day of menstruation. ${ }^{15}$ Estradiol $1.5 \mathrm{mg}$ (gel patch applied to the upper thigh or arm) was associated with a $22 \%$ reduction in migraine days (estradiol $=133 \mathrm{mi}$ graine days, placebo $=171$ migraine days; relative risk [RR] 0.78; CI 0.62-0.99, $p=0.04)$. This improvement was temporary, as subjects reported a $40 \%$ increase in migraine days in the 5 days following treatment (RR 1.40; CI 1.03-1.92, $p=0.03$ ). No serious AEs were otherwise reported, although common risks associated with estrogen supplementation are well documented throughout the literature. Limited studies are available regarding estrogen's safety specifically for long-term use in migraine prevention.

Hyperbaric oxygen. In a single Class II study, no differences were found between the HBO group (3 30-minute treatments/week) and control group, but an increase in headache hours was experienced by both groups vs the pretreatment level. ${ }^{16}$ Corrected for the number of days, the increase was 6.9 hours/ week for $\mathrm{HBO}$ vs 4.7 hours/week for controls. This study reports no assessment of tolerability or safety of
$\mathrm{HBO}$ vs control for migraine prevention.

Magnesium. In the original guideline, magnesium was found to be probably effective for migraine prevention on the basis of 2 positive Class II studies and 1 negative Class III study. Since the 2000 report, 1 additional Class II study compared the combination of magnesium $(300 \mathrm{mg})$, riboflavin $(400 \mathrm{mg})$, and MIG-99 (100 mg) with placebo (25 mg of riboflavin, which was thought to be a subtherapeutic dose but sufficient to provide urine discoloration to prevent unblinding of the study). ${ }^{17}$ Both treatment groups showed improvement over baseline, but no between-group differences were noted $(42 \%$ responders [defined as $\geq 50 \%$ reduction in attacks] in treatment group and $44 \%$ in placebo group; $p=$ $0.87)$. The study was not powered to show betweengroup differences and involved administration of magnesium only as combination therapy; thus, the results cannot be clearly interpreted regarding the efficacy of magnesium for migraine prevention. AEs were not reported.

MIG-99. MIG-99 is a relatively new stable extract of tanacetum parthenium (feverfew), which is reproducibly manufactured with supercritical $\mathrm{CO}_{2}$ from feverfew. In the original guideline, 3 positive studies and 1 negative study (feverfew given as alcohol extract) are reviewed that suggest possible efficacy for migraine prevention. Since the original guideline, 3 new studies on MIG-99 for migraine prophylaxis have been published. In 1 Class I study, the migraine frequency decreased from 4.76 by 1.9 attacks/month in the MIG-99 group and by 1.3 attacks in the placebo group $(p<0.05)$. A logistic regression analysis of responder rates showed an OR of 3.4 in favor of MIG-99 $(p<0.005) .{ }^{18}$ AEs reported were similar to those from placebo, the most common being gastrointestinal system disorders or respiratory system disorders.

In a Class II dose-finding study, MIG-99 $6.25 \mathrm{mg}$ TID (other doses tested: 2.08 and $18.75 \mathrm{mg}$ TID) was effective in reducing migraine frequency by 1.8 attacks/month (baseline $=4.5 \pm 0.8$ to $3.0 \pm 1.5$ attacks at week 12). The placebo group reduced migraine frequency by 0.3 attacks/month (baseline = $4.9 \pm 0.9$ to $4.6 \pm 2.2$ attacks at week $12 ; p=0.02$, CI 1.07-2.49). ${ }^{19}$

In a second Class II study, described above for magnesium, the efficacy of the combination of magnesium (300 mg), riboflavin (400 mg), and MIG-99 (100 mg) was not shown in comparison with a placebo (25 mg of riboflavin). ${ }^{17}$

Omega-3. One Class I study assessed the efficacy of omega-3 polyunsaturated fatty acids (3 g BID) vs placebo and found no difference in mean number of attacks during the last 4 weeks of the study (month 4 ), but the total number of attacks in 4 months was 
lower in the omega-3 treatment group. ${ }^{20} \mathrm{~A}$ very strong placebo effect was observed in this trial: $45 \%$ reduction of attacks between run-in and 4-month treatment period for placebo as compared with 55\% in the omega-3 group ( $p=0.058)$. AEs associated with omega- 3 treatment included significantly more frequent eructation $(8 \%)$ than with placebo $(1 \%)$; otherwise, no differences in AEs between treatments were reported.

Petasites. Petasites is a purified extract from the butterbur plant. Two Class I studies show Petasites (50-75 $\mathrm{mg}$ BID) to be effective in reducing migraine attack frequency. ${ }^{21,22}$ In the first study, the frequency of migraine attacks decreased by a maximum of $60 \%$ vs baseline, and the reduction in the number of migraine attacks vs placebo was significant $(p \leq$ $0.05) .{ }^{21}$ Petasites reduced the frequency of attacks from $3.3 \pm 1.5$ to $1.8 \pm 0.8$ attacks/month after 4 weeks, to $1.3 \pm 0.9$ attacks $/$ month after 8 weeks, and to $1.7 \pm 0.9$ attacks/month after 12 weeks $(p \leq$ $0.05)$. Following placebo, attack frequency decreased from $2.9 \pm 1.2$ to $2.2 \pm 0.7$ after 4 weeks $(p \leq$ $0.05)$, to $2.4 \pm 0.8$ after 8 weeks $(p \leq 0.05)$, and to $2.6 \pm 1.1$ after 12 weeks $(p \leq 0.05)$. No AEs were reported.

In the second Class I study, migraine attack frequency was reduced by $48 \%$ for Petasites extract 75 mg BID ( $p=0.0012$ vs placebo), by $36 \%$ for Petasites extract $50 \mathrm{mg}$ BID ( $p=0.127$ vs placebo), and by $26 \%$ for the placebo group. ${ }^{22}$ The incidence of burping increased for Petasites extract $75 \mathrm{mg}$ or 50 mg vs placebo. Importantly, safety of prolonged use of Petasites is not established by the short-term studies included in this review.

Riboflavin. In the original guideline, 1 Class I trial reported riboflavin to be superior to placebo, suggesting probable efficacy for migraine prevention. Since then, 1 additional Class II study (reviewed above) failed to show the efficacy of the combination of magnesium $(300 \mathrm{mg})$, riboflavin (400 mg), and MIG-99 (100 mg) vs $25 \mathrm{mg}$ of riboflavin. ${ }^{16}$

\section{CONCLUSIONS}

- Petasites is established as effective for migraine prevention (2 Class I studies).

- Riboflavin is probably effective for migraine prevention (1 Class I trial and 1 imprecise Class II study).

- Co-Q10 is possibly effective for migraine prevention (1 Class II study).

- A combination of soy isoflavones (60 mg), dong quai $(100 \mathrm{mg})$, and black cohosh (50 $\mathrm{mg}$ ) is possibly effective for migraine prevention (1 Class II study). Percutaneous estra- diol is possibly effective for migraine prevention (1 Class II study); however, there is an increased risk of migraine recurring after estradiol patch discontinuation.

- Magnesium is probably effective for migraine prevention (multiple Class II trials). MIG-99 (feverfew) is probably effective for migraine prevention (1 Class I study, 1 positive Class II study, and 1 underpowered negative Class II study).

- The efficacy of HBO for migraine prevention is unclear (1 imprecise negative Class II study).

- The efficacy of omega-3 for migraine prevention is unclear (1 imprecise Class I study).

RECOMMENDATIONS Level A. The following therapy is established as effective and should be offered for migraine prevention:

- Petasites (butterbur)

Level B. The following therapies are probably effective and should be considered for migraine prevention:

- NSAIDS: fenoprofen, ibuprofen, ketoprofen, naproxen, naproxen sodium

- Herbal therapies, vitamins, and minerals: riboflavin, magnesium, MIG-99 (feverfew)

- Histamines: histamine SC

Level C. The following therapies are possibly effective and may be considered for migraine prevention:

- NSAIDs: flurbiprofen, mefenamic acid

- Herbal therapies, vitamins, and minerals: CoQ10, estrogen

- Antihistamines: cyproheptadine

Level U. Evidence is inadequate or conflicting to support or refute the use of the following therapies for migraine prevention:

- NSAIDs: aspirin, indomethacin

- Herbal therapies, vitamins, and minerals: omega-3

- Other: $\mathrm{HBO}$

Level B negative. The following therapy is probably ineffective and should not be considered for migraine prevention:

- Leukotriene receptor antagonists: montelukast

CLINICAL CONTEXT In a previous epidemiologic study, $38.7 \%$ of study participants had ever used a migraine preventive treatment, of which only $12.4 \%$ were current users and $17.2 \%$ were coincident users (taking a migraine preventive treatment for other reasons). ${ }^{23}$ The proportion of those who use NSAIDs or individual complementary treatments specifically 
for migraine prevention is unclear at this time, and is a topic which warrants further study. Additionally, the treatments reviewed herein are those available in the United States. In other countries, treatments may not be available commercially or may be available in other dosages or in other preparations or combinations. Therefore, the results from this and other guidelines are limited to those treatments available in the United States.

Additionally, studies assessing the efficacy of NSAIDs and complementary treatments for migraine prevention are limited and should be considered relative to other available pharmacologic therapies reviewed in a separate guideline. ${ }^{4}$ Silberstein and colleagues report divalproex sodium, sodium valproate, topiramate, metoprolol, propranolol, and timolol are effective for migraine prevention and should be offered to patients with migraine to reduce migraine attack frequency and severity (Level A).

Additionally, the clinical evidence for NSAIDs and complementary treatments for migraine prevention should be reviewed with caution because there are clear discrepancies in how patients were selected for study inclusion; how severe, frequent, or disabling their attacks were; and how severity was assessed. Also, these treatments are unregulated. There are few or no studies on how these medications should be taken - specifically relative to dosing strategies and coadministration with other prescription pharmacologic treatments. When patients are instructed or choose to take NSAIDs or complementary treatments for migraine prevention, it is important that they be followed over the course of treatment so dosing and titration modifications and $\mathrm{AE}$ risk can be monitored. Prospective long-term safety of many of these agents is not well studied specifically regarding their use as preventive migraine treatments.

It is reasonable also for clinicians to inquire about the doses being used and frequency of use of NSAIDs and complementary treatments. Frequent medication use or high dose levels may increase the risk of headache progression or medication overuse, which may lead to other secondary health complications (e.g., gastrointestinal upset/bleeding with aspirin or NSAIDs or headache rebound with discontinuation of feverfew). Complete review and disclosure of coexisting conditions are warranted, as complementary or pharmacologic therapies taken for coexisting conditions (e.g., depression) may exacerbate headache. Because migraine is frequent in women of childbearing age, the potential for adverse fetal effects related to migraine prevention strategies is of particular concern. Little has been done to establish the long-term safety and efficacy of these agents during pregnancy or breastfeeding.

Additionally, when patients have unlimited access to over-the-counter medications, they may be unaware of the continued need for routine physician follow-up for a chronic illness such as migraine, as illness severity may progress or improve, often warranting medication changes (see table e-1). It also is important for patients to understand the magnitude of benefit that can be expected from preventive migraine therapies; moreover, patient education about migraine and appropriate management is important in successful patient care. For some patients, a $35 \%$ reduction in headache frequency or intensity may be deemed an insufficient level of improvement, thus leading them to risk dose escalation. Additionally, patients with migraine may need to be educated about appropriate use and risks of these agents.

Finally, recent studies suggest that some medications used for migraine may offer long-term protection against headache progression whereas other agents may elevate progression risk. Specifically, one epidemiologic study assessing medication use in the general migraine population reports that aspirin or ibuprofen use may protect against progression from episodic to chronic headache conditions. ${ }^{24}$ In contrast, opioid use was positively associated with chronic headache conditions. Although conclusions are preliminary regarding the benefits and risks of selected agents for long-term use, studies suggest that these agents may play a significant role in headache progression and patterns, lending further emphasis to the importance of following patients closely, including regular assessment of NSAIDs, and other complementary treatments for migraine prevention.

RECOMMENDATIONS FOR FUTURE RESEARCH Little is known about many of the NSAIDs and complementary treatments reviewed in this guideline; therefore, additional studies are needed to further understand the optimal doses of these migraine prevention treatments. Additionally, many of these treatments are readily available but not for migraine prevention, so little is known about increased $\mathrm{AE}$ risks when treatments are used one or more times daily for migraine prevention. More studies are needed that further assess the relative efficacy of these treatments in relation to other pharmacologic therapies. Other shortcomings of the existing evidence became apparent during this review and analysis, and several areas worthy of future investigation may include the following:

- Acceptability, long-term use, safety, and effectiveness of specific preventive therapies 
- Use of combination therapies, including drug therapy with behavioral treatment or combinations of 2 or more drugs

- Best duration for giving preventive treatment and how to discontinue treatment

- Predictors of remission with or response to preventive treatment

- Treatment of migraine and associated common comorbidities (e.g., depression, obesity, epilepsy, hypertension) and use of specific monotherapies or combination therapies in these patient subpopulations

- Development of stepped care and other treatment strategies for particular migraine headache types or particular migraine patient subgroups

- Compliance with preventive therapies

- Value of follow-up and patient education in disease management

- Use of preventive therapies to prevent illness progression (to chronic migraine)

- Effect of preventive treatments on acute therapy effectiveness

- The role of acute medication overuse in limiting the therapeutic efficacy of migraine preventive therapies

- Prospective trials that investigate standardized outcomes

\section{AUTHOR CONTRIBUTIONS}

Dr. Holland: manuscript preparation, drafting/revising the manuscript, study concept or design, analysis or interpretation of data. Dr. Silberstein: drafting/revising the manuscript, study concept or design, analysis or interpretation of data, study supervision. Dr. Freitag: drafting/revising the manuscript, analysis or interpretation of data, acquisition of data. Dr. Dodick: drafting/revising the manuscript, study concept or design, analysis or interpretation of data. Dr. Argoff: drafting/revising the manuscript, study concept or design, analysis or interpretation of data. Dr. Ashman: drafting/revising the manuscript, analysis or interpretation of data.

\section{DISCLOSURE}

Dr. Holland (formerly Dr. Pearlman) receives consulting income from Map Pharmaceuticals and the American Headache Society and research support from Albert Einstein College of Medicine. Dr. Silberstein is on the advisory panel of and receives honoraria from AGA, Allergan, Amgen, Capnia, Coherex, Colucid, Cydex, GlaxoSmithKline, Lilly, MAP, Medtronic, Merck, Minster, Neuralieve, NINDS, NuPathe, Pfizer, St. Jude Medical, and Valeant. He is on the speakers' bureau of and receives honoraria from Endo Pharmaceuticals, GlaxoSmithKline, and Merck. $\mathrm{He}$ serves as a consultant for and receives honoraria from Amgen and Novartis. His employer receives research support from AGA, Allergan, Boston Scientific, Capnia, Coherex, Endo Pharmaceuticals, GlaxoSmithKline, Lilly, MAP, Medtronic, Merck, NINDS, NuPathe, St. Jude Medical, and Valeant Pharmaceuticals. Dr. Freitag has served on the scientific advisory boards of Zogenix Pharmaceuticals, Allergan Pharmaceuticals, Nautilus, MAP Pharmaceuticals, and Nupathe; has received travel expenses and or honoraria from GlaxoSmithKline, Zogenix, Merck, Nautilus, Allergan, Diamond Headache Clinic Research and Educational Foundation (not for profit), and the American Headache Society (travel). Dr. Freitag is a member of the Board of Directors of the National Headache Foundation. Dr. Dodick, within the past 3 years, serves on advisory boards and has consulted for Allergan, Alder, Pfizer, Merck, Coherex, Ferring, Neuro- core, Neuralieve, Neuraxon, NuPathe Inc., MAP, SmithKlineBeecham, Boston Scientific, Medtronic, Inc., Nautilus, Eli Lilly \& Company, Novartis, Colucid, GlaxoSmithKline, Autonomic Technologies, MAP Pharmaceuticals, Inc., Zogenix, Inc., Impax Laboratories, Inc., Bristol Myers Squibb, Nevro Corporation, Atlas, Arteaus, and Alder Pharmaceuticals. Within the past 3 years, Dr. Dodick has received funding for travel, speaking, or editorial activities from CogniMed, Scientiae, Intramed, SAGE Publishing, Lippincott Williams \& Wilkins, Oxford University Press, Cambridge University Press, Miller Medical, Annenberg for Health Sciences; he serves as Editor-in-Chief and on the editorial boards of The Neurologist, Lancet Neurology, and Postgraduate Medicine; and has served as Editor-in-Chief of Headache Currents and as an Associate Editor of Headache; he receives publishing royalties for Wolff's Headache, 8th edition (Oxford University Press, 2009) and Handbook of Headache (Cambridge University Press, 2010). Within the past 3 years, Dr. Dodick has received research grant support from Advanced Neurostimulation Systems, Boston Scientific, St Jude Medical, Inc., Medtronic, NINDS/NIH, Mayo Clinic. Dr. Argoff has served on a scientific advisory board for the Department of Defense and DSMB for the NIH; has received funding for travel and/or speaking and/or has served on a speakers' bureau for Pfizer (King), Janssen (Pricara), Millennium Laboratories, Neurogesx, Forest Laboratories, Eli Lilly, Covidien, and Endo Pharmaceuticals; has received research support from Endo Pharmaceuticals, Forest Laboratories, Eli Lilly, Neurogesx, Pfizer, and SBRT funded by the NIH; and has received stock/stock options from Pfizer. Dr. Ashman is the Level of Evidence editor for Neurology and serves on the AAN Guideline Development Subcommittee. He reports no other disclosures. Full disclosures were provided at the time of Board approval. Go to Neurology.org for full disclosures.

\section{DISCLAIMER}

This statement is provided as an educational service of the American Academy of Neurology and the American Headache Society. It is based on as assessment of current scientific and clinical information. It is not intended to include all possible proper methods of care for a particular neurologic problem or all legitimate criteria for choosing to use a specific procedure. Neither is it intended to exclude any reasonable alternative methodologies. The AAN and the AHS recognize that specific patient care decisions are the prerogative of the patient and the physician caring for the patient, based on all of the circumstances involved. The clinical context section is made available in order to place the evidence-based guideline(s) into perspective with current practice habits and challenges. No formal practice recommendations should be inferred.

\section{CONFLICT OF INTEREST}

The American Academy of Neurology and the American Headache Society are committed to producing independent, critical and truthful clinical practice guidelines (CPGs). Significant efforts are made to minimize the potential for conflicts of interest to influence the recommendations of this CPG. To the extent possible, the AAN and AHS keep separate those who have a financial stake in the success or failure of the products appraised in the CPGs and the developers of the guidelines. Conflict of interest forms were obtained from all authors and reviewed by an oversight committee prior to project initiation. AAN and AHS limit the participation of authors with substantial conflicts of interest. The AAN and AHS forbid commercial participation in, or funding of, guideline projects. Drafts of the guidelines have been reviewed by at least three AAN and AHS committees, a network of neurologists, Neurology peer reviewers, and representatives from related fields. The AAN Guideline Author Conflict of Interest Policy can be viewed at www.aan.com.

Received June 27, 2011. Accepted in final form October 26, 2011.

\section{REFERENCES}

1. Lipton RB, Bigal ME, Diamond M, Freitag F, Reed ML, Stewart WF; The American Migraine Prevalence and Prevention Advisory Group. Migraine prevalence, disease burden, and the need for preventive therapy. Neurology 2007; 68:343-349. 
2. Ramadan NM, Silberstein SD, Freitag FG, Gilbert TT, Frishberg BM. Evidence-based guidelines for migraine headache in the primary care setting: pharmacological management for prevention of migraine. Available at: http://www.aan.com/professionals/practice/pdfs/gl0090. pdf. Accessed April 10, 2010.

3. Silberstein SD. Practice parameter: evidence-based guidelines for migraine headache (an evidence-based review): report of the Quality Standards Subcommittee of the American Academy of Neurology. Neurology 2000;55:754-762.

4. Silberstein SD, Holland S, Freitag F, Dodick DW, Argoff C, Ashman E. Evidence-based guideline update: pharmacologic treatment for episodic migraine prevention in adults: report of the Quality Standards Subcommittee of the American Academy of Neurology and the American Headache Society. Neurology 2012;78:1337-1345.

5. Millán-Guerrero RO, Isais-Millán R, Benjamín TH, Tene CE. N-alpha-methyl histamine safety and efficacy in migraine prophylaxis: phase III study. Can J Neurol Sci 2006;33:195-199.

6. Millán-Guerrero RO, Isais-Millán R, Barreto-Vizcaíno S, et al. Subcutaneous histamine versus sodium valproate in migraine prophylaxis: a randomized, controlled, doubleblind study. Eur J Neurol 2007;14:1079-1084.

7. Millán-Guerrero RO, Isais-Millán R, Barreto-Vizcaíno S, et al. Subcutaneous histamine versus topiramate in migraine prophylaxis: a double-blind study. Eur Neurol 2008;59:237-242.

8. Rao BS, Das DG, Taraknath VR, Sarma Y. A double blind controlled study of propranolol and cyproheptadine in migraine prophylaxis. Neurol India 2000;48:223-226.

9. Brandes JL, Visser WH, Farmer MV, et al. Montelukast for migraine prophylaxis: a randomized, double-blind, placebo-controlled study. Headache 2004S;44:581-586.

10. Diener HC, Hartung E, Chrubasik J, et al; Study group. A comparative study of oral acetylsalicylic acid and metoprolol for the prophylactic treatment of migraine: a randomized, controlled, double-blind, parallel group phase III study. Cephalalgia 2001;21:120-128.

11. Benseñor IM, Cook NR, Lee IM, Chown MJ, Hennekens $\mathrm{CH}$, Buring JE. Low-dose aspirin for migraine prophylaxis in women. Cephalalgia 2001;21:175-183.

12. Silberstein SD, Olesen J, Bousser MG, et al; International Headache Society. The International Classification of Headache Disorders, 2nd Edition (ICHD-II): revision of criteria for 82 Medication-overuse headache [erratum in 2006;26:360]. Cephalalgia 2005;25:460-465.

13. Sandor PS, Di Clemente L, Coppola G, et al. Efficacy of coenzyme Q10 in migraine prophylaxis: a randomized controlled trial. Neurology 2005;64:713-715.
14. Burke BE, Olson RD, Cusack BJ. Randomized, controlled trial of phytoestrogen in the prophylactic treatment of menstrual migraine. Biomed Pharmacother 2002;56:283288.

15. MacGregor EA, Frith A, Ellis J, Aspinall L, Hackshaw A. Prevention of menstrual attacks of migraine: a doubleblind placebo-controlled crossover study. Neurology 2006; 67:2159-2163.

16. Eftedal OS, Lydersen S, Helde G, White L, Brubakk AO, Stovner LJ. A randomized, double blind study of the prophylactic effect of hyperbaric oxygen therapy on migraine. Cephalalgia 2004;24:639-644.

17. Maizels M, Blumenfeld A, Burchette R. A combination of riboflavin, magnesium, and feverfew for migraine prophylaxis: a randomized trial. Headache 2004;44:885-890.

18. Pfaffenrath V, Diener HC, Fischer M, Friede M, Henneicke-von Zepelin HH. The efficacy and safety of Tanacetum parthenium (feverfew) in migraine prophylaxis-a double-blind, multicentre, randomized placebocontrolled dose-response study. Cephalalgia 2002;22: 523-532.

19. Diener HC, Pfaffenrath V, Schnitker J, Friede M, Henneicke-von Zepelin HH. Efficacy and safety of 6.25 $\mathrm{mg}$ tid feverfew $\mathrm{CO} 2$-extract (MIG-99) in migraine prevention-a randomized, double-blind, multicentre, placebo-controlled study. Cephalalgia 2005;25:10311041.

20. Pradalier A, Bakouche P, Baudesson G, et al. Failure of omega-3 polyunsaturated fatty acids in prevention of migraine: a double-blind study versus placebo. Cephalalgia 2001;21:818-822.

21. Grossman W, Schmidramsl H. An extract of Petasites hybridus is effective in the prophylaxis of migraine. Altern Med Rev 2001;6:303-310.

22. Lipton RB, Gobel H, Einhaupl KM, Wilks K, Mauskop A. Petasites hybridus root (butterbur) is an effective preventive treatment for migraine. Neurology 2004;63:22402244.

23. Diamond S, Bigal ME, Silberstein S, Loder E, Reed M, Lipton RB. Patterns of diagnosis and acute and preventive treatment for migraine in the United States: results from the American Migraine Prevalence and Prevention study. Headache 2007;47:355-363.

24. Scher AI, Lipton RB, Stewart WF, Bigal M. Patterns of medication use by chronic and episodic headache sufferers in the general population: results from the frequent headache epidemiology study. Cephalalgia 2010;30: 321-328.

Endorsed by the American Osteopathic Association on March 22, 2012. 


\section{Neurology}

Evidence-based guideline update: NSAIDs and other complementary treatments for episodic migraine prevention in adults: Report of the Quality Standards Subcommittee of the American Academy of Neurology and the American Headache Society

S. Holland, S.D. Silberstein, F. Freitag, et al. Neurology 2012;78;1346-1353

DOI 10.1212/WNL.0b013e3182535d0c

This information is current as of April 23, 2012

Neurology $®$ is the official journal of the American Academy of Neurology. Published continuously since 1951, it is now a weekly with 48 issues per year. Copyright Copyright $@ 2012$ by AAN Enterprises, Inc.. All rights reserved. Print ISSN: 0028-3878. Online ISSN: 1526-632X.

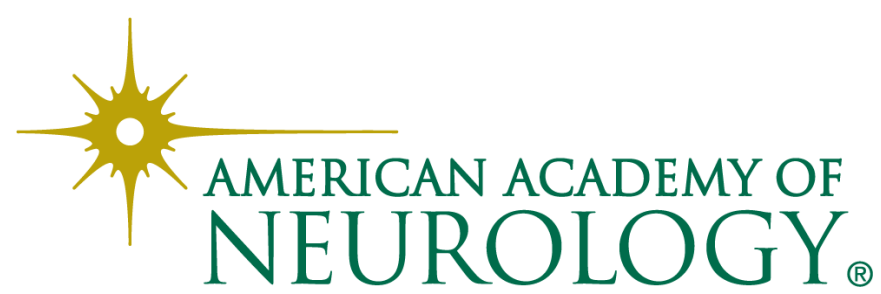




\section{Updated Information \& Services}

\section{Supplementary Material}

\section{References}

\section{Citations}

Subspecialty Collections

\section{Permissions \& Licensing}

Reprints including high resolution figures, can be found at:

http://www.neurology.org/content/78/17/1346.full.html

Supplementary material can be found at:

http://www.neurology.org/content/suppl/2012/04/22/78.17.1346.DC1.h tml

http://www.neurology.org/content/suppl/2012/04/22/78.17.1346.DC2.h tml

http://www.neurology.org/content/supp1/2012/11/01/78.17.1346.DC3.h tml

This article cites 23 articles, 13 of which you can access for free at: http://www.neurology.org/content/78/17/1346.full.html\#\#ref-list-1

This article has been cited by 4 HighWire-hosted articles: http://www.neurology.org/content/78/17/1346.full.html\#\#otherarticles

This article, along with others on similar topics, appears in the following collection(s):

\section{Migraine}

http://www.neurology.org//cgi/collection/migraine

Palliation pain

http://www.neurology.org//cgi/collection/palliation_pain

Information about reproducing this article in parts (figures,tables) or in its entirety can be found online at:

http://www.neurology.org/misc/about.xhtml\#permissions

Information about ordering reprints can be found online: http://www.neurology.org/misc/addir.xhtml\#reprintsus

Neurology $₫$ is the official journal of the American Academy of Neurology. Published continuously since 1951, it is now a weekly with 48 issues per year. Copyright Copyright @ 2012 by AAN Enterprises, Inc.. All rights reserved. Print ISSN: 0028-3878. Online ISSN: 1526-632X.

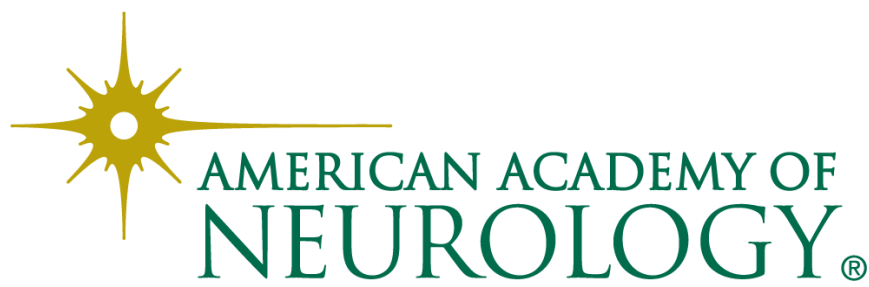




\section{Neurology}

\section{Evidence-based guideline update: NSAIDs and other complementary treatments for episodic migraine prevention in adults: [RETIRED]: Report of the Quality Standards Subcommittee of the American Academy of Neurology and the American Headache Society}

S. Holland, S.D. Silberstein, F. Freitag, et al. Neurology 2012;78;1346-1353

DOI 10.1212/WNL.0b013e3182535d0c

This information is current as of April 23, 2012

\section{Updated Information \& Services}

Citations

Subspecialty Collections

Permissions \& Licensing

Reprints including high resolution figures, can be found at: http://n.neurology.org/content/78/17/1346.full

This article has been cited by 8 HighWire-hosted articles: http://n.neurology.org/content/78/17/1346.full\#\#otherarticles

This article, along with others on similar topics, appears in the following collection(s):

Migraine

http://n.neurology.org/cgi/collection/migraine

Palliation pain

http://n.neurology.org/cgi/collection/palliation_pain

Information about reproducing this article in parts (figures,tables) or in its entirety can be found online at:

http://www.neurology.org/about/about_the_journal\#permissions

Information about ordering reprints can be found online:

http://n.neurology.org/subscribers/advertise

Neurology ${ }^{\circledR}$ is the official journal of the American Academy of Neurology. Published continuously since 1951, it is now a weekly with 48 issues per year. Copyright Copyright (? 2012 by AAN Enterprises, Inc.. All rights reserved. Print ISSN: 0028-3878. Online ISSN: 1526-632X.

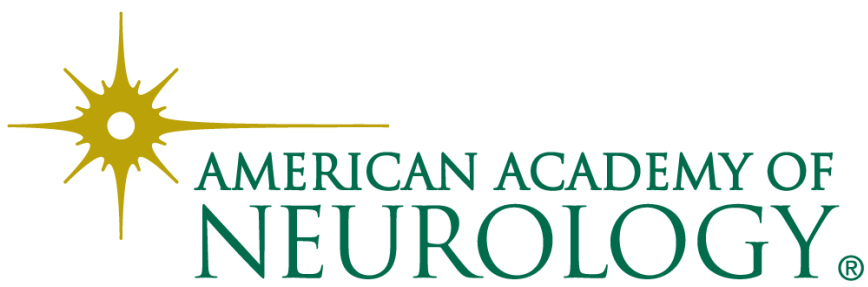

